allowed $15 \sec$ after delivery to consume the five pellets. Trials were terminated by removing the $S$ from the goal section and placing him in the ITI box for $20 \mathrm{sec}$ before beginning the next trial.

Extinction trials were begun on the day following a given group's last day of acquisition training. All $\mathrm{Ss}$ received 8 days of extinction, six trials per day. The procedure used during extinction was the same as that used in acquisition with two exceptions: (a) when $S$ entered the goal section on a predetermined D-trial (I and D sequence determined by the same procedure as in acquisition) the guillotine door was immediately lowered and the delay period plus $15 \mathrm{sec}$ was allowed to elapse before removal, and (b) when $S$ entered the goal section on an I trial confinement lasted for 15 sec only. During extinction Groups D60 and DV received their respective delay lengths but were never reinforced.

\section{RESULTS AND DISCUSSION}

To test for equivalence of delay groups for a given level of acquisition, $t$ tests were performed on total latencies for the first and last days of acquisition. Results indicate that delay groups within levels of acquisition did not differ significantly on any of these days.

Analysis of variance tests were performed on total extinction latencies within each level of training (start, run, and goal latencies show identical overall results and are not included). Total extinction latencies at the 24-trial level show a significant extinction effect $[F(7,84)=7.88, p<.01]$ and a significant Delay by Extinction Trials interaction $[F(7,84)=2.59, \quad p<.05]$. Inspection of Fig. 1 indicates that across extinction trials, D60 and DV groups diverged, with Group DV becoming the more resistant to extinction. This result is significant in the direction opposite that predicted by the aftereffects hypothesis.

Extinction latencies for groups at the 60-trial level show a significant extinction trials effect $[F(7,84)=4.79, p<.01]$ and a significant Delay by Extinction Trials interaction $\quad[F(7,84)=3.60, \quad p<.01]$. Inspection of Fig. 1 indicates that delay groups diverge across trials with Group D60 becoming relatively more resistant to extinction, confirming aftereffects prediction.

Latencies at the 120-trial level show a significant delay main effect $[F(1,12)=6.26, p<.05]$ and a significant extinction trials effect $[F(7,84)=7.00$, $p<.01]$. These results and inspection of Fig. 1 indicate that Group DV was more resistant to extinction than Group D60, again confirming the aftereffects predictions.

Taken as a whole, the results of the present experiment generally provide support for the aftereffects hypothesis. The

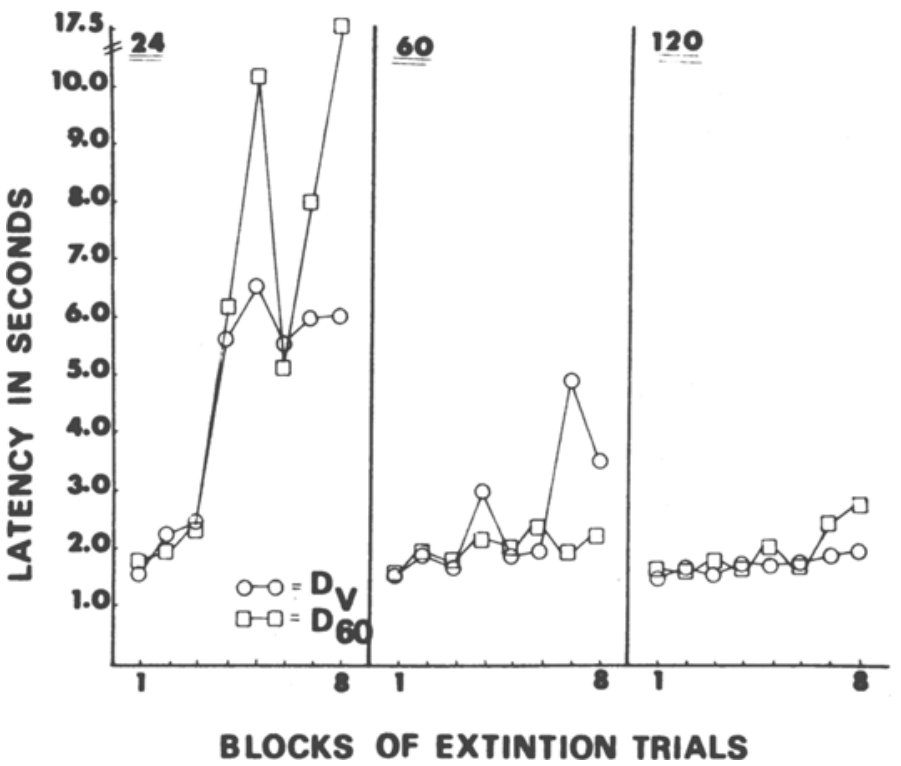

Fig. 1. Total runway latencies during extinction.

predicted switch in relative resistance to extinction occurring in the 60-and 120-trial groups can, at best, not be easily explained by other current theories. Although the data for the 24-trial groups was significant in the direction opposite to prediction, it is difficult to evaluate the importance of this result for the aftereffects hypothesis since selection of $\mathrm{N}$-length and $\mathrm{D}$-length variables was completely arbitrary. Interestingly, results at the 24-trial level and the observed switch in relative resistance to extinction from 24- to 60-trial groups cannot easily be explained by current nonsequential theories.
REFERENCES

CAPALDI, E. J. Effect of N-length, number of different $\mathbf{N}$-lengths and number of reinforcements on resistance to extinction. Journal of Experimental Psychology, 1964, 68, 230-239.

CAPALDI, E. J. Partial reinforcement: A hypothe sis of sequential effects. Psychological Review, 1966, 73, 459-477.

CAPALDI, E. J., \& SPIVEY, J. E. Intertrial reinforcement and aftereffects at 24-hour intervals. Psychonomic Science, 1964, 1, 181-182.

CAPALDI, E. J., \& STANLEY, L. R. Temporal properties of reinforcement. Journal of Experimental Psychology, 1963, 65, 169-175.

\title{
The absolute behavioral taste threshold for sodium saccharin in the rat'
}

JEROME S. STUMPHAUZER and RUTH ANN WIL LIAMS, Florida State University, Tallahassee, Fla. 32306

The absolute taste threshold for sodium saccharin was determined in four rats using a behavioral taste discrimination shockavoidance technique. The threshold concentrations which were obtained varied from $4 \times 10^{-5} \mathrm{M}$ to $1.2 \times 10^{-4} \mathrm{M}$, with an average value of $8 \times 10^{-5} \mathrm{M}$. As might be expected, these absolute threshold concen- 
trations were lower than the sodium saccharin preference thresholds reported for rats and were similar to the absolute threshold reported for humans.

Sodium saccharin $\left(\mathrm{C}_{6} \mathrm{H}_{4} \mathrm{CONSO}_{2} \mathrm{Na}\right)$ is a chemical which has been of interest to many psychologists because of its sweet taste to humans, its preference by many animals, and its supposedly nonnutritive quality (see Warren \& Warren; 1966). These aspects of sodium saccharin have made it a popular tool in experiments dealing with motivation, reinforcement, and taste (e.g., Capretta, 1964; Sheffield \& Roby, 1950; Warren \& Pfaffmann, 1959). In many such experiments the rat has been used as a S. Yet the absolute taste threshold of the rat for sodium saccharin has not been reported. The present study was designed to determine the rat's absolute taste threshold for sodium saccharin.

The taste threshold was determined for each rat using a behavioral taste discrimination, shock-avoidance method similar to those of Carr (1952) and Harriman \& MacLeod (1953).

\section{SUBJECTS}

The Ss were five experimentally naive female albino rats from the Florida State University colony. One rat ceased responding after the first shock trial. Attempts to recover the behavior of this rat were unsuccessful. Therefore, threshold values could be obtained for only four of the rats. APPARATUS

The apparatus consisted of a taste discrimination box with grid floor, wooden walls, and a clear Plexiglas top. The inside dimensions of the box measured $11 \times 6 \times 8$ in. Two water bottles were attached to the exterior of one end of the box and their metal drinking tubes protruded into the box through two holes in the wall.

A $325 . \mathrm{V}$ dc shock source was wired in series with a variable $0-10$ megohm resistor. When the rat was drinking from the tube, closure of a switch completed the circuit through the rat from the metal tube to the grid floor. The level of shock was determined empirically for each rat by first setting an initial level of 10 megohms, then gradually decreasing the resistance until the $S$ avoided the tube. The final resistance setting was 3.0 megohms for one $S$ and 0.5 megohms for three Ss.

The molar concentrations of sodium saccharin in distilled water used in the experiment were: $4 \times 10^{-3}, 3 \times 10^{-3}$, $2 \times 10^{-3}, 1.2 \times 10^{-3}, 8 \times 10^{-4}, 4 \times 10^{-4}$, $3 \times 10^{-4}, 2 \times 10^{-4}, 1.2 \times 10^{-4}, 8 \times 10^{-5}$, $4 \times 10^{-5}, 2 \times 10^{-5}$.

\section{PROCEDURE}

All Ss had ad lib Purina chow but nowater in their home cages during the experiment.
Table 1

Absolute Behavioral Taste Thresholds of Four Rats for Sodium Saceharin

\begin{tabular}{rcc}
\hline$S$ & $\begin{array}{c}\text { Per cent } \\
\text { Concentration* }\end{array}$ & $\begin{array}{c}\text { Molar } \\
\text { Concentration }\end{array}$ \\
\hline 1 & .002 & $8 \times 10^{-5}$ \\
2 & .001 & $4 \times 10^{-5}$ \\
3 & .003 & $1.2 \times 10^{-4}$ \\
4 & .002 & $8 \times 10^{-5}$ \\
\hline Mean & .002 & $8 \times 10^{-5}$ \\
\hline
\end{tabular}

* Grams per $100 \mathrm{ml}$ of solution

Throughout the experiment water was available only in the discrimination box. For the first 5 days each $S$ was placed in the discrimination box once every $12 \mathrm{~h}$ for an adaptation session. During these sessions both tubes contained distilled water and the rat could drink from either tube. A session consisted of 10 trials, each trial consisting of $10 \mathrm{sec}$ of drinking from either tube. $\mathrm{S}$ was removed from the box for approximately $10 \mathrm{sec}$ between trials. At the end of each session the rat was given about 2 min of free access to the water tubes in the box.

On the 6th day and the 11 th session discrimination training was begun. The highest concentration in the descending series of sodium saccharin solutions was introduced in one of the drinking tubes. This concentration was easily detectable and within the preferred range. If on a given trial $S$ began ingesting the saccharin solution and continued to drink the solution for $5 \mathrm{sec}$, an electric shock was delivered. This generally resulted in avoidance of the solution and the rat then drank from the water tube for the allotted $10 \mathrm{sec}$. If, instead, $S$ persisted in drinking the solution, more shocks were given at $5-\sec$ intervals for a total of not more than three shocks on a given trial. If $S$ began any trial by ingesting distilled water, she was permitted her usual $10 \mathrm{sec}$ of water drinking before that trial was terminated. If $S$ 's initial choice was saccharin and $S$ switched to the water tube before $5 \mathrm{sec}$ had elapsed (thereby avoiding shock), she was given $10 \mathrm{sec}$ access to the water. Ten such discrimination trials with 10 -sec intertrial intervals were given each session. The positions of the saccharin and water tubes were randomly varied throughout each session. At the end of the second session each day $S$ was permitted about 2 min free access to the water tube.

If $S$ received no more than one shock in each of two successive sessions, discrimination between the distilled water and saccharin solution at that particular concentration was considered to be achieved. During the following session the next lower concentration of saccharin was introduced until the same criterion was met. If after 20 sessions ( 10 days and 200 trials) $\mathrm{S}$ did not meet criterion at a particular concentration, the experimental trials for that $S$ were terminated. Threshold was defined as the lowest concentration of solution at which criterion for discrimination was met. Both the criterion for discrimination and the criterion for termination of trials were identical to those of Harriman \& MacLeod (1953).

\section{RESULTS AND DISCUSSION}

The obtained threshold concentrations are reported in Table 1 . The individual thresholds varied from $4 \times 10^{-5} \mathrm{M}$ to $1.2 \times 10^{-4} \mathrm{M}$ or from .001 to $.003 \%$. The mean threshold concentration was $8 \times 10^{-5} \mathrm{M}$ or $.002 \%$.

What might be termed "neurotic" behavior was noted as each $S$ neared threshold and after threshold had been reached. The following are some of the behaviors observed as finer and finer discriminations were required: (1) increases in grooming behavior, (2) increases in exploratory behavior, (3) licking the wall below the tubes, (4) biting the tubes and grid floor.

The results of this study are well within the range of what one might expect. The average sodium saccharin detectability threshold found here was considerably lower than the average preference threshold of $9 \times 10^{-4} \mathrm{M}$ obtained by Ables \& Benjamin (1960) and that of $3 \times 10^{-3} \mathrm{M}$ graphed by Fisher, Pfaffmann, \& Brown (1965). Also, it was relatively close to the human detectability threshold of $3 \times 10^{-5} \mathrm{M}$ reported by Fisher et al (1965).

\section{REFERENCES}

ABLES, M. F. \& BENJAMIN, R. M. Thalamic relay nucleus for taste in albino rat. Journal of Neurophysiology, 1960, 23, 376-382.

CAPRETTA, P. J. Saccharin consumption and the reinforcement issue. Journal of Comparative \& Physiological Psychology, 1964, 57, 448-450.

CARR, W. J. The effect of adrenalectomy upon the $\mathrm{NaCl}$ taste threshold in rat. Joumal of Comparative \& Physiological Psychology, 1952. 45, 377-380.

FISHER, G. L., PFAFFMANN, C., \& BROWN, E. Dulcin and saccharin taste in squirrel monkeys, rats, and men. Science, $1965,150,506-507$.

HARRIMAN, A. E., \& MacLEOD, R. B. Discriminative thresholds of salt for normal and adrenalectomized rats. American Journal of Psychology, 1953, 66, 465-471.

SHEFFIELD, F. D., \& ROBY, T. B. Reward value of a non-nutritive sweet taste. Journal of Comparative \& Physiological Psychology, 1950, 43,471-481.

WARREN, R. M., \& PFAFFMANN, C. Suppression of sweet sensitivity by potassium gymnemate. Journal of Applied Physiology, $1959,14,40-42$

WARREN, R. P., \& WARREN, R. M. Soluble saccharin preference: A nutritive basis for persistence. Nature, 1966, 210, 310-311. NOTE

1. This research was submitted by the first author in partial fulfillment of the requirements for a course at Florida State University entitled Experimental Analysis of Behavior, directed by Robert W. Schaeffer and the second au thor. 